\title{
Personalized and Adaptive Learning
}

\author{
Deborah L. Taylor, Michelle Yeung, and A. Z. Bashet
}

Personalized and adaptive learning is currently implemented in a variety of ways. To explore the topic and how it might be applied to STEM disciplines, meet Keisha Johnson, our hypothetical student, and Professor Jones, who is implementing personalized adaptive learning techniques into the classroom. Using their shared story, we will provide definitions, benefits, impact, opportunities, challenges, and future research initiatives while showcasing the choices required by the institution, faculty, and students.

Keisha Johnson, a pre-nursing major, knows that she needs to earn high grades in all of her classes in order to be accepted into a competitive nursing program. Keisha is a scholarship student attending a large university in her state. She was a stellar high school student but is worried because she graduated from an urban school system that has a reputation of having underprepared students for the challenges of college. Her major concern at this point is that she is starting her second year of classes at the University and has enrolled in Human Physiology, a required but very challenging course that has a reputation as a weed-out class. Keisha is also worried that she won't be able to keep up with the work and might not be able to pass a large class with more than 200 students enrolled due to the possible lack of individualized attention from the instructor.

\footnotetext{
D. L. Taylor $(\bowtie)$

University of Kansas, Lawrence, KS, USA

e-mail: dtaylor@ku.edu

M. Yeung

Loyola Marymount University, Los Angeles, CA, USA

e-mail: Michelle.Yeung@lmu.edu
}

\author{
A. Z. Bashet \\ Dallas County Community College District, Dallas, TX, USA \\ e-mail: azbashet@dcccd.edu
}


On the first day of class, Professor Anna Jones makes an announcement to the class that they will be using an adaptive, personalized system for their assignments. She explains to her students how the system assesses each individual's prior knowledge before lecture and then directs content delivery and practice questions to create a learning path that is individualized for every student.

Keisha is intrigued by Professor Jones' explanation that adaptive learning is a type of personalized learning made possible by the use of computers. The adaptive learning system delivers assessments that evaluate students' prior knowledge and then using artificial intelligence prescribes individualized learning content in a sequential manner that is designed to meet the learning needs of each individual. After hearing how the adaptive and personalized learning system works, Keisha becomes quite excited. This sounds like a game-changer to her. She knows that she is a hard worker and likes the idea of having resources personalized to her learning needs.

\section{Emerging Trends and Pedagogies}

\subsection{Defining Personalized and Adaptive Learning}

In personalized learning, instructional approaches are customized to individual learners. Feldstein (2016) noted that personalized learning is what you do, not how you do it. While it is possible to achieve personalized learning in a classroom, it is quite a daunting challenge to personalize instruction when there are more than a few students in the class. Yet, it is now feasible to bring personalized learning to scale utilizing the affordances of adaptive learning technologies. As a result of the changing face of education, computer technology has greatly affected the pedagogy of higher education. The computer has gone from simply being a conduit for delivering course content to students to one that continuously identifies the learning needs of each student and provides individualized learning paths in real time.

Unfortunately, at this time, in the academic environment, the concept of adaptive learning is nebulous. Cavanagh et al. (2020) emphasize that the lack of clear and consistent terminology throughout the educational arena presents a stumbling block for adaptive learning implementation in higher education. There is an effort to clarify "what" adaptive learning is, and yet the technologies that provide adaptive learning vary so much that it is daunting to even identify what should be included in the definition. Adaptive learning technology provides personalized learning at scale by assessing learners' current skills/knowledge, providing feedback and content, and then constantly monitoring progress by utilizing learning algorithms that provide real-time updates and the necessary tools to improve student learning (Educause Learning Initiative 2017). The Horizon Report (2018) explains that adaptive learning occurs when digital tools and systems are used to create individual learning 
paths for students based on their strengths, weaknesses, and pace of learning. While this definition is accepted by many, others (Cavanagh et al. 2020; Pugliese 2016) note that the taxonomy is still quite fluid, thus making it difficult to gain consensus on a working definition.

Some adaptive learning systems include profile information from other sources, but most advanced systems create a learning path at the time of interaction with the student. The student's activity profile, learning analytics data, and machine learning then allow the tools to monitor progress and create continuous adjustment to learning paths in real time, in addition to providing personalized scaffolding to promote learning for each student and targeting individualized intervention for improving student success. Adaptive learning environments provide instructors the tools to utilize technologies and data to provide timely feedback on student performance. In describing adaptive learning systems, Mavroudi et al. (2018) quoted Froschl's definition used in his masters' thesis: "in an adaptive system the needs of the learner are assumed by the system itself and, thus, it adjusts its behavior accordingly" (p. 2). In more formal language, Paramythis and Loidl-Reisinger (2004: 182) note that "a learning environment is considered adaptive if it is capable of: monitoring the activities of its users; interpreting these on the basis of domain-specific models; inferring user requirements and preferences out of the interpreted activities, appropriately representing these in associated models; and, finally, acting upon the available knowledge on its users and the subject matter at hand, to dynamically facilitate the learning process."

\subsection{Pedagogies of Adaptive Learning}

Pedagogy is defined as the methods and practice of teaching (https://www.lexico. com/en/definition/pedagogy). Personalized and adaptive learning are driving a change in higher education from instructor-centered pedagogies to student-centered pedagogies.

Student-centered learning (also known as learner-centered pedagogy) is based on constructivist learning theory and supports student learning by allowing students to make decisions in their learning (Goodman et al. 2018; Hannafin and Land 1997; Wright 2011). Dockterman's (2018) overview of the history of personalized learning informs us that students learn more effectively when instruction is individualized to the learners' needs and that a new pedagogy of personalization recognizes that each student is different. Bringing that pedagogy to scale, however, requires technological intervention that until now has not been available. Identifying students' needs and providing scaffolding for learning are in the heart of adaptive learning platforms. Scaffolding is defined as the support and guidance provided to the learner until the learner can accomplish a task or demonstrate competence independently (Wood et al. 1976).

"Chunking" of content is an online pedagogical approach guided by cognitive information processing (CIP) research that states, in order to reduce cognitive load 
and enhance learning, information must be broken down into small manageable "chunks" (Mayer 2005). Adaptive learning content delivery is driven by this online pedagogical approach.

Student learning is enhanced when learners are encouraged to evaluate their learning (metacognition), and many adaptive systems employ tools that allow the students to monitor their progress with some systems offering directed metacognitive experiences for the student as he or she moves through the lessons. Adaptive learning technologies promote learning by utilizing the method of retrieval learning which is often called "testing to learn" (Lindsey et al. 2014; Bae et al. 2019; Miller and Geraci 2016; Thomas et al. 2018). An initial assessment of prior knowledge directs the delivery of content and the scaffolding that addresses the learner's needs with continuous assessments in real-time updates and the learning data constantly allowing for the development of an individualized learning pathway for each student. Retrieval learning and metacognition are components of cognitive learning theories.

Online learning design plays a major role in the design of adaptive learning course development. Cavanagh et al. (2020) developed and shared a blueprint for a design framework as well as a pedagogical approach for adaptive learning that can serve as a starting point for institutions considering adopting an adaptive learning technology for course delivery.

\subsection{Emerging Technologies}

Emerging technologies enabling personalized and adaptive learning include learning analytics, artificial intelligence, machine learning, intelligent tutors, adaptive controls, and robust interactive learning content (Groff 2017; Mavroudi et al. 2018; Murray and Pérez 2015). Adaptive learning platforms provide students a flexible learning environment that can accelerate learning by creating an individualized learning path directed by prior knowledge and continuous assessment of performance. In the 2017 Horizon Report, Adams Becker, Cummins, Davis, Freeman, Hall, and Ananthanarayanan identified adaptive learning technologies as one of the six developments of educational technologies that will have the greatest impact in institutions of higher education. However, the 2019 Horizon Report noted concerns that the expectations for progress were not yet met. Alexander et al. (2019:35) suggest that the failure to meet expectations may be due to the fact that "Technology tools were felt to be in their infancy, creating a large investment from the institution of time, money, and resources." Yet, the rapid evolution of information processing and Internet technologies enables e-learning to provide personalization, interactivity, media-rich content, just-in-time delivery, and a learner-centered environment where students can take ownership of their learning. Advances in technologies present new opportunities for adapting instruction to individual learning paths. According to the 2017 New Media Consortium (NMC) Horizon Report-Higher Education Edition, "the increasing focus on customizing instruction to meet students' unique needs is driving the development of new technologies." 
Adaptive learning technologies can be classified as adaptive learning platforms and adaptive learning programs. The adaptive learning platforms exist as standalone systems, where all courseware functionalities are bundled into one robust working unit, whereas adaptive learning programs provide a component that can plug into an existing course in an LMS and deliver the adaptive and personalized experience. Either the adaptive systems can provide content developed by the vendor or the systems can merely serve as a framework for institutions to input their own content.

Pugliese (2016) noted that many promising opportunities exist where adaptive learning technology can enhance student learning and success. Adaptive learning technologies can support content created by a vendor, publisher, or institution. There are pros and cons to each of the options, and it falls to the instructor and institution to sort out which to use based upon institutional resources, availability, quality of the content, and usability of the technology. The adaptive mechanisms vary as well. Currently there are four categories of adaptive learning systems, and all integrate learning objectives, instructional resources, and assessments into modules for learning. The four frameworks (from simplest to most complex) are decision tree adaptive systems, rule-based adaptive systems, advanced algorithm-based adaptive systems, and machine learning-based adaptive systems. A short list of some of the emerging adaptive technologies currently used in higher education includes Smart Sparrow, Knewton, CogBooks, Cengage Mindtap, and Realizeit.

Personalizing learning at scale is made possible by powerful computer processing assessment data, interaction data, and learning behavior data for each student in order to create feedback, scaffolding, and continuous assessment that deliver the individualized learning paths. Adaptive learning systems can inform instructors early in the course, even before the first exam, as the student's activity and performance in the course are continuously monitored and assessed in formative assessments. Information can be sent to the instructor, and early intervention methods can be utilized to catch an at-risk student before it is too late, thus reducing attrition and increasing student success. "Adaptive systems address the fundamentally different levels of prior knowledge, as well as course content progression based on students' skill and outcomes mastery measurement, decreasing faculty load in teaching and remediation to teaching and facilitating" (Pugliese 2016).

\section{Use of Personalized and Adaptive Learning in 2026}

\subsection{Content Presentation}

The adaptive learning system develops a learning path for each student and delivers individualized content based upon assessments of performance. One of the more critical requirements is that of delivering the content into "bite-sized" chunks that allow evaluation of bits of knowledge that are then compiled into a learning plan. 
The adaptive learning system tracks performance and monitors behaviors during the time of interaction and then delivers the adaptive content in an adaptive sequence individualized for each learner. A robust adaptive learning system offers multiple options for the modality of the content delivery, e.g., text, video, or interactive activities. Some adaptive systems have the capacity to analyze performance and determine if the student learns better by interactive activities, watching videos, or reading and then deliver the content in the ideal format that is associated with that student's improved performance.

\subsubsection{Opportunities}

In adaptive learning, content delivery is guided by student performance and prior knowledge, thus providing a more personalized experience and promoting student engagement (Dziuban et al. 2016). Kerr (2016) demonstrated that when the adaptive learning systems deliver content in the format determined by assessment to be the best for that student's learning, student learning is enhanced. Additionally, Meccawy et al. (2007) showed that integrating content presentation with learner interaction enhances student engagement and success.

Most adaptive learning systems are accessed through cloud services providing the students with access to course content when they are ready to learn thus enabling student-centered learning, promoting learning autonomy, and encouraging selfregulated learning. Another important component of an adaptive learning system is the ability to provide remediation should a student not have the prior knowledge needed to perform well in the class. This affordance assists underprepared students to gain the knowledge while still in the course, thus not slowing down their forward educational momentum (Dziuban et al. 2016).

\subsubsection{Challenges}

The adaptive learning technology field is so young that there are no set standards for these tools. This can result in confusion for those wanting to implement this new technology. Some tools offer some adaptive opportunities, but the adaptive options vary considerably from system to system. Many institutions and faculty find it a very real challenge to select the tool that best meets their needs. While many would prefer to develop their own content, the time and costs to do so are a real challenge to institutions and faculty.

\subsubsection{Implementation Strategies}

The recognized value of adaptive learning courseware in the university system to increase student success has prompted numerous initiatives from the Association of Public and Land-Grant Universities (APLU). One initiative is the formation of the 
Personalized Learning Consortium (PLC), a membership organization charged with increasing information on using technology and personalizing learning in order to promote student success. In addition, the APLU, with funding from the Bill \& Melinda Gates Foundation, created a grant opportunity for universities to accelerate the adoption of adaptive courseware by public institutions. Eight universities piloted the process of adopting, implementing, and scaling adaptive courseware. One byproduct of this initiative was the development of a tool for faculty, instructional designers, and administrators of postsecondary institutions to effectively navigate the market of courseware solutions. Recognizing that the selection of courseware is contextual, with the course context playing a critical role in guiding the selection and implementation of courseware, the Online Learning Consortium, Tyton Partners, and the Gates Foundation developed the Courseware in Context (CWiC) Guide (coursewareincontext.org) to assist institutions in the complex process of evaluating and selecting the appropriate adaptive learning courseware for their courses. SRI International aligned the framework for efficacy research. Education of stakeholders is a major component of the CWiC Guide, and suggestions for implementation are guided by the defined needs of that institution.

\subsubsection{Research Questions}

Several research questions were proposed at the X-FILEs workshop regarding content presentation and delivery. However, research answering all of the posed questions was found in current literature. This phenomenon supports the premise that adaptive learning is so new that current knowledge is somewhat nebulous. It appears that many, if not most, of the participants did not fully understand the current status of adaptive learning. One of the questions was "How are policies at various institutions determined for selecting and purchasing the content delivery tools?" which is addressed by the APLU's Implementing Adaptive Courseware Guide (2017).

Each morning, Professor Jones pulls up the data on student performance on the assignment for that day and identifies topic areas where students performed poorly. She then adjusts her lecture later that day in order to focus on the content topics that the students found most challenging and reduces the amount of time for the content that the students already know to a minimum.

\subsection{Interactions and Communications}

Interactions and discussions have been shown to be a vital part of student learning. From the time of Plato up to the present, students have depended upon interactions and communication with one another and with their instructors to facilitate learning. The range and depth of interactions and communication and the modality vary 
greatly across the learning environment. Very few stand-alone adaptive learning systems include opportunities for students to communicate and work collaboratively with other students. Adaptive learning programs that only deliver adaptive learning activities are typically used in conjunction with other teaching modalities in order to facilitate interactions between and among students. The component systems delivering the adaptive learning activities can be used in online, blended, and face-to-face courses to enhance student-centric learning. Interactions and communications in most adaptive learning programs are limited to those between the student and the program, with the exceptions mentioned above offered by only a few robust adaptive learning systems.

\subsubsection{Opportunities}

Students can choose when they work, and because the assignments are automatically graded, they can receive immediate feedback and scaffolding as needed. A major component of adaptive learning tools is that of feedback and scaffolding. Initially the student is assessed for knowledge, and the results of this assessment guide the delivery of structured feedback and scaffolding as well as new content. Ideally this process offers a student the opportunity to move through the course content at a pace that is determined by his/her prior knowledge as well as the amount of time he/she puts into the learning process. However, typically these adaptive tools are used in conjunction with a regular class (online or face-to-face), but it is not beyond the scope of adaptive learning to develop courses that allow students to complete a course more quickly than a typical semester period. These self-paced courses offer flexibility of scheduling, but do present challenges as explained below. There are some institutions of higher education now offering self-paced courses, but these do not typically consist of adaptive learning software.

The instructor dashboards allow instructors to monitor student progress and identify students who are having problems early in the course so that intervention can occur in a timely manner. The student dashboards allow students to track their progress through the learning materials and promote self-regulation of learning, and some programs even offer metacognitive assessments to enhance the learning experience.

\subsubsection{Challenges}

For a student to benefit from an adaptive learning system, he or she must initiate interaction with the system, sustain engagement, and successfully complete the assigned activities. A student working in an adaptive learning environment brings a number of behavioral factors into play that affect the interactions with the course content. The internal student-level factors that influence student behavior in an adaptive learning system can be examined from the perspective of motivational theory. It has been shown that engagement, self-determination theory, autonomy, 
self-regulation, and the level of internal motivation are positively associated with student learning. The action of initiating engagement is driven by motivational factors. Reeve (2012) notes "self-determination theory is unique in that it emphasizes the instructional task of vitalizing students' inner motivational resources as a key step in facilitating high-quality engagement."

As mentioned above, many fully inclusive adaptive software systems do not offer student-to-student interactions nor student-to-instructor interactions. This could result in the student feeling isolated if no compensating adjustments were offered.

\subsubsection{Implementation Strategies}

Adaptive software programs can be used to offer supplemental learning opportunities for the traditional classroom as well as in the fully online environment. Many of the fully adaptive platforms do not offer student-to-student interaction, and if this type of interaction is to be a part of the course, it is often necessary to utilize the communication opportunities offered by a traditional learning management system.

\subsubsection{Research Questions}

One research question asked in the workshop was: "Can personalized avatars be used to deliver the feedback and scaffolding to lessen the students' feelings of isolation?" Kim (2012) proposed guidelines for designing virtual change agents (VCAs) (avatars) that would promote student learning needs in a personalized manner in online remedial math courses. The strategies were based on motivational learning theories and the interactions between the student and the VCA.

As the semester progresses, Keisha enjoys doing many of the interactive assignments. She likes receiving immediate feedback on her performance and guidance for her study in order to provide efficient use of her time. Keisha even enjoys the metacognitive component of each question and the ability to track her progress through the course. She recognizes the value of the learning resources and takes time to do additional review assignments that the program provides that focus on what she had missed before but limits material that she has already mastered.

\subsection{Learner Activities}

Prior knowledge assessments are typically the first activity that the learners encounter in an adaptive learning environment. Results from these assessments guide the development of an individualized learning path that provides personalized content 
delivery for each student based on their strengths and weaknesses. This content can range from simplistic fill-in-the-blanks to more sophisticated scenario-based learning activities. The importance of engaging students in learning activities is paramount. In many of the adaptive learning systems, the content included in the system replaces a textbook, meaning that all of the learning occurs via the interactions with the adaptive learning system. The learning activities delivered to each student are determined by the results of assessments, thus creating differing learning paths. Students receive different learning opportunities by the adaptive learning system as it analyzes student knowledge and scaffolding needs (Meccawy et al. 2007). Learning activities that engage interactive animations of complex processes (e.g., cell division) with questions interspersed in the activities increase student engagement.

\subsubsection{Opportunities}

Adaptive learning systems have the capacity to provide targeted information based on individual learning needs (Peter et al. 2010), provide appropriate scaffolding (Raes et al. 2012), and personalize activities based on student responses (Chen 2011; Normandhi et al. 2019; Blair et al. 2016).

Gephardt (2018) studied the effect of utilizing adaptive learning courseware on student performance in an Economics course at Colorado State University as part of an Association of Public and Land-Grant Universities (APLU). She found that the "students who completed low-stakes adaptive assessments outperformed their peers who did not complete the adaptive assignment on easy and moderate questions on the exam that could result in a higher course grade. This suggests that if adaptive learning courseware is integrated as low-stakes assignments then student outcomes improved with relatively little effort on both sides of the instructor and the students" (p. 16).

\subsubsection{Challenges}

Providing engaging, robust, and applicable learning activities that address the learning outcomes is probably the most challenging aspect of building an adaptive learning experience (excluding building the learning platform). Following that is the ability to develop appropriate feedback and purposeful scaffolding that free the student from needing assistance from the instructor in order to move forward in his or her learning path.

\subsubsection{Implementation Strategies}

There is often resistance to accept this modality by the faculty due to training needs and time to set up the system (in those that are modifiable). Alignment with course content is challenging since many faculty members determine the content for their 
own courses. Therefore, it would be important that the system allows for adaptation by the instructor to give him/her ownership. The University of Central Florida modeled an excellent approach in developing and delivering adaptive content in their pilot program (Dziuban et al. 2016). However, it needs to be mentioned that the administration was behind the project and provided a great deal of financing, not only to pay the faculty to develop the content but also to pay graduate teaching assistants and instructional design support to reduce the workload of the faculty. Any institution considering building their own content would do well to explore what the UCF has done.

\subsubsection{Research Questions}

One question from the 3-day X-FILEs workshop was: "What learning activities are most effective in promoting student engagement and learning?" Linnenbrink and Pintrich (2003) determined that relevant and relatable activities promote student engagement and learning. Additionally, Van Lehn (2011) showed that utilizing an adaptive learning experience promoted student engagement and learning. Therefore, a valuable area of research would be that of examining student behaviors such as persistence, self-regulation, internal motivation, and engagement and see if the adaptive learning systems can capture that data correctly and determine if student learning is affected.

Dr. Jones designed her class so that the adaptive learning system assignments are due the evening before each class begins. This prepares the students for learning to occur during class by remediating those who were lacking in knowledge needed to address new material.

\subsection{Assessment}

The most effective adaptive learning systems initially assess the student's prior knowledge followed by continuous formative assessment as well as guidance as the student moves through the course content (EdSurge 2016). Dziuban et al. (2018) proposed that adaptive learning acts like a GPS for students. It allows for personalized instruction by altering students' pathways through course objectives. In addition, adaptive learning systems continually assess students' knowledge, guiding them to efficiently and effectively progress through the course.

In conjunction with the creation of a personalized learning path is the requirement of mastery of the material (Gebhardt 2018). Mastery learning requires clear measurable learning objectives, an idea of what mastery of that learning objective entails, learning activities that assess the mastery, and a means of tracking and sharing the information to direct learning. STEM courses depend upon learning new 
content based upon prior knowledge, and a student moving forward in a lesson without mastering the concepts is a recipe for failure. Adaptive learning provides the assessment tools and evaluation options that can assure mastery of content, not only at the time of new content delivery but periodically checking the continued mastery throughout the learning path.

\subsubsection{Opportunities}

Adaptive learning courseware can significantly reduce the amount of time a student takes to complete a course when evaluation of prior knowledge shows mastery of that content. The individualized learning pathway provided by the adaptive learning courseware can allow the student to move forward to the next module at a pace that is suitable for him or her. If gaps in knowledge are revealed, a robust adaptive learning platform provides remediation as needed, including appropriate feedback and scaffolding.

Grading open-ended questions such as essays, projects, etc. to assess higherorder thinking skills in didactic curricula of large classes can be onerous. Quite often, instructors use multiple-choice questions (MCQs). However, creating higherorder thinking questions in MCQ format is very challenging and time-consuming because typically a scenario, case study, or fairly complex problem needs to be described and three or four plausible, but incorrect choices created. Aguilar et al. (2006) proposed a computer-based adaptive assessment tool designed to use formative and summative assessments developed by teachers allowing them to use the information to perform real-time evaluations of the learners' levels of understanding. Adaptive learning systems take the process one step further by removing the instructors' tasks of evaluating the information to determine the levels of student understanding as well as providing scaffolding to support the learner where needed, thus freeing them up to have more personal contact with the students.

Formative assessments are efficient for both instructors and students to assess learning in personalized and adaptive learning environments. Instructors can check students' understanding through formative assessment and collect valuable data on student learning and then use that data to modify instruction. Godfrey (2006) found that incorporation of computer-based assessment increased student engagement in learning and instructors believed technology-enhanced assessment tools positively impacted their teaching.

Technology-enabled assessments including assistive technology emerged as potentially powerful mechanisms for measuring growth mindsets or behavioral attributes of students as they engage in the learning process (West 2011). The Information Research Corporation developed an integrated technology platform eTouchSciences to support STEM learning that includes devices that provide multiple forms of feedback, including tactile, visual, and audio, to the student (Thomas 2016). Examples of technology-enabled personalized and adaptive assessment tools used in higher education include Carnegie Mellon University's Cognitive Tutor 
Software, Pearson's MyLabs, McGraw-Hill's ALEKS Online Tutoring System and LearnSmart, and Australia's SmartSparrow.

Intelligent tutoring systems are some of the earliest adaptive learning technologies, and they offer personalized and interactive learning experiences that help students engage in learning more effectively than traditionally based instructional methods. This technology tool enables personalization of learning and evaluation of performance in real time. Intelligent tutoring systems enhance students' engagement and individual learning experiences by providing immediate and adjusted feedback based on each student's learning progression and his or her actions and responses to given questions and lesson activities (Thomas 2016). Adaptive learning systems go one step further to supply scaffolding to add to those interactive experiences in order to enhance learning.

\subsubsection{Challenges}

Verification of identity is a must. It is very important to ensure that it is really the student doing the work. There are a number of methods to verify identity; however, many are quite costly to the student or institution.

Formative assessments composed of multiple-choice questions, including immediate feedback and scaffolding for learning, can be delivered via learning management systems or adaptive learning tools and can be readily directed by teachers. Formative assessment with feedback and scaffolding becomes more challenging when one incorporates critical thinking and complex problem-solving (Spector et al. 2016: 59). The value of formative assessment cannot be denied, yet the overemphasis on summative assessment has resulted in inadequate resources for formative assessment (Ecclestone 2010; Sadler and Good 2006).

\subsubsection{Implementation Strategies}

Instructor training and professional development opportunities are paramount to implementing a successful adaptive learning endeavor. The University of Central Florida (UCF) and Georgia State University provide excellent examples of instructor training to promote adaptive learning in their institutions. The UCF developed a support network of instructional designers, technical experts, and content experts to assist faculty in developing courses using adaptive learning, and to further enhance the onboarding experience, they developed a self-paced training course for faculty (Cavanagh et al. 2020). Georgia State offered a comprehensive adaptive learning workshop to foster faculty buy-in and commitment. They found that providing support as needed and building a community of inquiry enhanced the implementation of adaptive learning using the funds received from the APLU Learning Grant (Tesene 2018). Developing and delivering formative assessments require extensive time and resources, yet this is a must for a successful implementation if an institution hopes to build its own adaptive learning content. 


\subsubsection{Research Questions}

A powerful research question is addressed in the literature and is worth mentioning here. That one question was: "What pedagogical tools in adaptive learning environments best promote student engagement (and outcomes)?" Scaffolding is one of the most important pedagogical tools utilized in adaptive learning. Scaffolding is described as the structure of content and feedback in such a manner that the student can work through the lessons without requiring intervention from an instructor, thus promoting autonomy and self-direction. A well-designed adaptive learning platform offers a robust experience with numerous branching options supported by scaffolding to allow students to work independently (Raes et al. 2012).

Professor Jones compared the performance of recent students in her course using adaptive learning with that of students from classes before she implemented the active learning component. She was able to quantify a significant increase in student pass rates and a decrease in course attrition after she integrated the learning activities into her course.

\subsection{Co-curricular Activities}

Co-curricular activities are learning experiences offered outside the classroom that allow students to expand their interests and perhaps even gain skills that would prepare them for their careers. Co-curricular should not be confused with extracurricular activities like sports and performance opportunities. Co-curricular learning experiences add depth to what is occurring in the classroom, yet are not typically graded. Co-curriculars include leadership skills training, service learning, and study abroad.

\subsubsection{Opportunities}

Co-curricular activities could easily provide personalization of a student's educational path and the chance to apply and implement lessons learned without interfering with the set academic path the most institutions require. A menu of adaptive learning minicourses could offer students opportunities to gain skills adjacent to their primary courses, thus providing a personalized option of learning opportunities that are not part of the program curriculum. 


\subsubsection{Challenges}

One challenge is to ensure the safety of students participating in co-curricular activities while on and off campus. Another challenge is that many students at large universities have difficulties knowing what opportunities are available to them.

\subsubsection{Implementation Strategies}

Researchers at the University of Washington discovered that students had difficulty finding co-curricular opportunities because they used many different sources to get information. A recommendation from the study was to address the student context and offer information at several different levels.

\subsubsection{Research Questions}

Many of the participants at the X-FILEs workshop were unfamiliar with what cocurricular offerings were, and all questions posed were already answered in the literature.

\section{Conclusions}

Personalized and adaptive learning offers great opportunities to promote student learning, yet it presents a number of challenges that instructors and institutions will need to address in order for an adaptive learning implementation to be successful. The first step is to identify what problems are being addressed in implementing an adaptive learning adoption and after that what "right" adaptive learning approach and system are needed to be determined. Will an add-on component to be used with existing courses within various learning management systems solve the problems that are driving the move to adopt adaptive learning, or is a fully independent adaptive learning platform needed? Questions of compatibility with the current learning management systems will need to be answered if the former option is chosen. Additionally, while decisions to implement an adaptive learning approach are typically made by the institution's administrators, yet without faculty buy-in, it is highly unlikely that a successful outcome will occur. Engaging faculty early in the process is advised coupled with institution-wide engagement increasing the possibility of a successful outcome (Implementing Guide 2017: 2). 
At the end of the semester, Keisha is one of the top-scoring students in the class and has received notice that she was accepted into the nursing program. She is hoping that the nursing courses she will need to take will provide learning resources that are adaptive and personalized like the physiology course she just completed. However, adaptive and personalized courses are limited by the resources at a school. And there are still some areas that require additional research to be sure that time and money spent on these courses result in better student outcomes.

\section{References}

Adams Becker SA, Cummins M, Davis A, Freeman A, Hall C, Ananthanarayanan V (2017) NMC Horizon Report: 2017 Higher Education Edition. The New Media Consortium, Austin. http:// cdn.nmc.org/media/2017-nmc-horizon-report-he-EN.pdf

Aguilar G, Gomez A, Kaijiri K (2006, October) Adaptive teaching and learning using a classroom communication system and an adaptive computer-based assessment tool. In: E-learn: world conference on E-learning in corporate, government, healthcare, and higher education. Association for the Advancement of Computing in Education (AACE), pp 2701-2706

Alexander B, Ashford-Rowe K, Barajas-Murph N, Dobbin G, Knott J, McCormack M et al (2019) EDUCAUSE Horizon Report 2019 Higher Education Edition. EDU19, pp 3-41

Bae CL, Therriault DJ, Redifer JL (2019) Investigating the testing effect: Retrieval as a characteristic of effective study strategies. Learning and Instruction 60:206-214

Blair E, Maharaj C, Primus S (2016) Performance and perception in the flipped classroom. Education and information Technologies 21(6):1465-1482

Cavanagh TL, Chen B, Lahcen RAM, Paradiso JR (2020) Constructing a design framework and pedagogical approach for adaptive learning in higher education: a practitioner's perspective. Int Rev Res Open Distrib Learn 21(1):172-196

Chen LH (2011) Enhancement of student learning performance using personalized diagnosis and remedial learning system. Computers \& Education 56(1):289-299

Dockterman D (2018) Insights from 200+ years of personalized learning. NPJ Sci Learn 3(1):1-6

Dziuban CD, Moskal PD, Cassisi J, Fawcett A (2016) Adaptive learning in psychology: wayfinding in the digital age. Online Learn 20(3):74-96

Dziuban C, Moskal P, Parker L, Campbell M, Howlin C, Johnson C (2018) Adaptive learning: a stabilizing influence across disciplines and universities. Online Learn 22(3):7-39

Ecclestone K (2010) Transforming formative assessment in lifelong learning. McGraw-Hill Education, Berkshire

Edsurge (2016) Decoding adaptive. Pearson. Retrieved from https://www.pearson.com/corporate/ about-pearson/innovation/smarter-digital-tools/adaptive-learning.html

Educause Learning Initiative (2017) 7 things you should know about Adaptive Learning. https:// library.educause.edu/ /media/files/library/2017/1/eli7140.pdf. Accessed 14 Jan 2019

Feldstein M, Hill P (2016) Personalized learning: What it really is and why it really matters. Educause review 51(2):24-35

Gebhardt K (2018) Adaptive learning courseware as a tool to build foundational content mastery: Evidence from principles of microeconomics. Current Issues in Emerging eLearning 5(1):2

Godfrey C (2006) The impact of a classroom communication system on the learning process in eighth-grade special education classes. ARE 5(1)

Goodman BE, Barker MK, Cooke JE (2018) Best practices in active and student-centered learning in physiology classes. AJP Adv Physiol Educ 42(3):417-423 
Groff J (2017) Personalized learning: the state of the field \& future directions. Center for Curriculum Redesign

Hannafin MJ, Land SM (1997) The foundations and assumptions of technology-enhanced studentcentered learning environments. Instr Sci 25(3):167-202

Implementing adaptive courseware: a guide to courseware development, use and evaluation based on the collaborative experience of four public research universities (2017) Personalized Learning Consortium. https://www.aplu.org/library/implementing-adaptive-courseware/File

Kerr P (2016) Adaptive learning. ELT J 70(1):88-93. https://doi.org/10.1093/elt/ccv055

Kim C (2012) The role of affective and motivational factors in designing personalized learning environments. Educ Technol Res Dev 60(4):563-584

Lindsey RV, Shroyer JD, Pashler H, Mozer MC (2014) Improving students' long-term knowledge retention through personalized review. Psychol Sci 25(3):639-647

Linnenbrink EA, Pintrich PR (2003) The role of self-efficacy beliefs in student engagement and learning in the classroom. Read Writ Q 19:119-137

Mavroudi A, Giannakos M, Krogstie J (2018) Supporting adaptive learning pathways through the use of learning analytics: developments, challenges and future opportunities. Interact Learn Environ 26(2):206-220

Mayer RE (2005) Introduction to multimedia learning. The Cambridge handbook of multimedia learning 2:1-24

Meccawy M, Brusilovsky P, Ashman H, Yudelson M, Scherbinina O (2007, October) Integrating interactive learning content into an adaptive e-learning system: lessons learned. In: E-learn: world conference on E-learning in corporate, government, healthcare, and higher education. Association for the Advancement of Computing in Education (AACE), pp 6314-6319

Miller T, Geraci L (2016) The influence of retrieval practice on metacognition: the contribution of analytic and non-analytic processes. Conscious Cogn 42:41-50

Murray MC, Pérez J (2015) Informing and performing: a study comparing adaptive learning to traditional learning. Inf Sci 18:111

Normandhi NBA, Shuib L, Nasir HNM, Bimba A, Idris N, Balakrishnan V (2019) Identification of personal traits in adaptive learning environment: Systematic literature review. Computers \& Education 130:168-190

Paramythis A, Loidl-Reisinger S (2004) Adaptive learning environments and e-Learning standards. Electron J e-Learn 2(1):181-194

Peter SE, Bacon E, Dastbaz M (2010) Adaptable, personalised e-learning incorporating learning styles. Campus-Wide Inf Syst 27(2):91-100

Pugliese L (2016) Adaptive learning systems: surviving the storm. EDUCAUSE Review. https:// er.educause.edu/articles/2016/10/adaptive-learning-systems-surviving-the-storm

Raes A, Schellens T, De Wever B, Vanderhoven E (2012) Scaffolding information problem solving in web-based collaborative inquiry learning. Comput Educ 59(1):82-94

Reeve J (2012) A self-determination theory perspective on student engagement. In: Christenson S, Reschly A, Wylie C (eds) Handbook of research on student engagement. pp 149-172

Sadler PM, Good E (2006) The Impact of self and peer-grading on student learning. Educational Assessment 11(1):1-31

Spector JM, Ifenthaler D, Sampson D, Yang JL, Mukama E, Warusavitarana A et al (2016) Technology enhanced formative assessment for 21 st century learning. J Educ Technol Soc 19(3):58-71

Tesene MM (2018) Adaptive selectivity: a case study in evaluating and selecting adaptive learning courseware at Georgia State University. Curr Issues Emerg eLearn 5(1):6. https://scholarworks. umb.edu/ciee/vol5/iss $1 / 6$

Thomas S (2016) Future ready learning: reimagining the role of technology in education. 2016 National Education Technology Plan. Office of Educational Technology, US Department of Education. http://tech.ed.gov/ 
Thomas RC, Weywadt CR, Anderson JL, Martinez-Papponi B, McDaniel MA (2018) Testing encourages transfer between factual and application questions in an online learning environment. Journal of Applied Research in Memory and Cognition 7(2):252-260

Van Lehn K (2011) The relative effectiveness of human tutoring, intelligent tutoring systems, and other tutoring systems. Educ Psychol 46(4):197-221

West DM (2011) Using technology to personalize learning and assess students in real-time. Brookings Institution, Washington, DC

Wood D, Bruner JS, Ross G (1976) The role of tutoring in problem solving. Journal of child psychology and psychiatry 17(2):89-100

Wright GB (2011) Student-centered learning in higher education. Int J Teach Learn High Educ 23(1):92-97

Open Access This chapter is licensed under the terms of the Creative Commons Attribution 4.0 International License (http://creativecommons.org/licenses/by/4.0/), which permits use, sharing, adaptation, distribution and reproduction in any medium or format, as long as you give appropriate credit to the original author(s) and the source, provide a link to the Creative Commons license and indicate if changes were made.

The images or other third party material in this chapter are included in the chapter's Creative Commons license, unless indicated otherwise in a credit line to the material. If material is not included in the chapter's Creative Commons license and your intended use is not permitted by statutory regulation or exceeds the permitted use, you will need to obtain permission directly from the copyright holder.

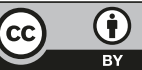

